Research Article

\title{
Knowledge and Attitude of Dental Clinicians towards Light-Curing Units: A Cross-Sectional Study
}

\author{
Dana Al-Senan $\left(\mathbb{D},{ }^{1}\right.$ Fatin Ageel $\mathbb{D},{ }^{2}$ Amani Aldosari $\left(\mathbb{D},{ }^{2}\right.$ and Haifa Maktabi $\mathbb{D}^{2}$ \\ ${ }^{1}$ Department of Clinical Dental Science, Faculty of Dentistry, Princess Nourah Bint Abdulrahman University, \\ Riyadh, Saudi Arabia \\ ${ }^{2}$ Department of Restorative Dentistry, Prince Sultan Military Medical City, Riyadh, Saudi Arabia
}

Correspondence should be addressed to Dana Al-Senan; dfalsenan@pnu.edu.sa

Received 28 January 2021; Accepted 5 June 2021; Published 15 June 2021

Academic Editor: Sivakumar Nuvvula

Copyright (c) 2021 Dana Al-Senan et al. This is an open access article distributed under the Creative Commons Attribution License, which permits unrestricted use, distribution, and reproduction in any medium, provided the original work is properly cited.

Objectives. Light curing is crucial when applying composite resin restorations. Complete polymerization of the resin depends on delivering adequate light energy to it. Dental clinicians may be unaware of the importance of proper light-curing techniques. This study aimed at evaluating and comparing the level of knowledge of general practitioners (GPs) and specialists (SPs) regarding light-curing units. Materials and Methods. An electronic survey was conducted online among GPs and SPs of various specialties, working in the governmental sector in Riyadh, Saudi Arabia. Collected data were analyzed for statistical significance. Results. 310 dentists were included in the study. Nearly half of the GPs (45.9\%) and more than half of SPs (56.8\%) use light-emitting diode (LED) type light-curing units (LCUs). $36.9 \%$ of GPs and 29.6\% of SPs were unsure about the type of LCUs they use in their dental clinics. $10.8 \%$ of GPs and $8.5 \%$ of SPs knew the proper term of the power output of LCU. $52.2 \%$ of the GPs and $55.7 \%$ of SPs were wrong about advancements in technology of LED LCUs. Regarding the use of radiometer, $48.2 \%$ of SPs and $35.1 \%$ of GPs had responded wrongly, and $37.7 \%$ of SPs and $52.3 \%$ of GPs were not familiar with the device, showing a statistical significance $(p=0.040)$. There was no statistical significance observed in the responses pertaining to their years of experience, expected for two questions. Conclusion. Both GPs and SPs displayed inadequate knowledge regarding the use of LCUs. Further educational programs are recommended to spread awareness about the handling of LCUs among dental clinicians.

\section{Introduction}

The use of composite resins is increasing dramatically for anterior and posterior restorations due to its better esthetic outcome, improved longevity, and high mechanical properties [1-3]. Even though these restorative materials have gained popularity over the past few years, the failure rate is higher than anticipated. Several factors affect the polymerization of a composite resin restoration: technical factors such as the irradiance and type of Light-Curing Unit (LCU), material-related factors such as the resin shade and thickness, and operator factors such as the light tip position and exposure time [4].

LCU plays an important role in the clinical success of resin-based composite (RBC) restorations. Inadequate polymerization of RBC adversely affects the resin's physical and mechanical properties, decrease the wear resistance, increase microleakage, lead to recurrent caries, and show color instability $[5,6]$. However, some dental clinicians lack awareness of the importance of a proper light-curing technique and its impact on the success of the composite restoration [7].

Quartz-Tungsten-Halogen (QTH), Plasma Arc Curing (PAC), Light-Emitting diode (LED), and Argon laser are the four different blue light curing units that are available nowadays in the market. They are used to activate the photoinitiators in the resin materials by producing photons of light $[8,9]$. QTH were well known in the past and had a halogen bulb that needed to be cooled frequently, and a fan that helped disperse the unwanted heat away from the bulb. Although they delivered a broad emission spectrum, they required an exposure time of 30 to 40 seconds to cure a $2 \mathrm{~mm}$ 
increment of resin material, which generated a large amount of heat that affected the life span of the device $[10,11]$.

PAC lights were introduced in an attempt to reduce the light exposure time. Although they delivered high irradiance, they had multiple tips to provide different power outcomes which created a confusion among clinicians. They were also known to be expensive and difficult to be moved around. On the other hand, argon ion lasers generate very intense emission peaks in the blue spectral region, but they became less popular due to several reasons like nonportability, inability to function on batteries, and being expensive [12].

In the early 1990s, LED were introduced. They were light weighted, battery driven, cordless, and required less maintenance [12]. Three generations of LED are available today. The first and second generations emit blue light in a wavelength between 410 and $470 \mathrm{~nm}$ but are unable to properly cure resin material with an alternative photoinitiator other than camphorquinone (the most common photoinitiator in resin materials). A third generation LED was developed to overcome this issue, which emits light at a wavelength between 380 and $515 \mathrm{~nm}$ and is capable of photocuring the new photoinitiators which were introduced to allow fabricating lighter shades of RBCs [13].

Different shades of RBCs are available providing a wide selection range for better matching of tooth structures. Manufactures' that recommend increasing the exposure time while using darker shades, support the idea that less light penetrates through composites with more opaque shades [14]. Research also found that when the thickness of the increment increases, the overall radiance exposure is reduced [15]. Increasing the curing time for a longer period than manufacturer's recommendations resulted in higher microhardness values and positive effect on DC (degree of conversion) [16, 17].

Additionally, appropriate infection-control methods must be taken to prevent cross-infection.

A barrier must be used to cover LCUs. However, these plastic barriers will reduce the irradiance from the LCU, so the light exposure time must be increased accordingly [18].

The distance between the light-curing unit tip and the surface of the resin material is one of the important factors to be considered since a reduction in radiance power was observed when the distance was increased [19].

Maintenance of LCUs is required to be done because, with lack of monitoring, its quality diminishes over time resulting from heat buildup within the unit, bulb frosting, tip contamination with remnants of composite resin, and sterilization problems. It is recommended to use a radiometer to measure the power output before each clinical session $[20,21]$.

The knowledge and awareness of dental clinicians regarding the proper use of light-curing units were addressed in several studies internationally [22-24]. A study was conducted among private clinics in Saudi Arabia which showed that dentists expressed poor knowledge, maintenance, and attitude toward LCUs, with most of them reporting that they did not measure the light intensity output [25]. Alshaafi et al. performed a study to evaluate the light intensity output of QTH and LED curing devices located at eight governmental health institutions in Riyadh, Saudi Arabia. The study found that LCU devices fell below the satisfactory value of light intensity and it was recommended that the regular assessment of LCUs was to be made mandatory [26].

The previous literature has highlighted an issue that needs to be considered to minimize any clinical error with regard to LCUs and inadequate polymerization of RBCs. Large number of dentists in Riyadh are working in governmental hospitals and there is a lack of information pertaining to dental clinician's knowledge and awareness about LCUs. The current study aimed at evaluating the knowledge levels of dental practitioners in governmental jobs in Riyadh, Saudi Arabia, regarding the LCUs, and comparing this information between specialists and general dentists.

\section{Materials and Methods}

A cross-sectional survey was conducted over a duration of two months, among general dentists and specialist of various specialties, working in the governmental sector in Riyadh, Saudi Arabia, and who use LCUs often. Only dental clinicians working in governmental sectors in Riyadh were included in this study. The targeted population size was 500, which resulted in a calculated sample size of 310 dental clinicians. Calculation was performed at the $95 \%$ confidence level.

The research approval was obtained from Princess Nourah Bint Abdulrahman University Institutional Review Board with the reference number H-01-R-059.

A questionnaire, hosted on the "Google Forms" platform, was distributed electronically via e-mail, social media channels, and personal contacts to dentists. The questionnaire comprised of eighteen questions over three sections. The first section entailed the demographic data including age, gender, type and location of practice, qualification, and years of experience. The second section comprised five questions covering LCU types and their latest advancement, proper positioning technique, and irradiance. It also included two questions covering material science, i.e., the effect of insufficient radiant exposure on RBC properties, and how to overcome any reduction in power output. The third section included four questions related to maintenance, safety, and infection control of the light-curing units, i.e., whether they inspect LCUs before clinical use, the use of radiometer to monitor output, the use of eye protection, and techniques of infection control.

Validation of our questions was performed by inviting 5 experts to validate each question of the survey over a scale of 4 rank: the question is not relevant, the question is somewhat relevant, the question is quite relevant, or the question is highly relevant.

Statistical analyses were carried out using SPSS version 26.0 statistical software (IBM Inc., Chicago, USA). Pearson's correlation coefficient was used to compare the categorical responses of knowledge and practice in relation to the study variables. Chi-square test was done to determine the 
significant difference between a general dentist and a specialist. A $p$ value of $<0.05$ was considered statically significant.

\section{Results}

3.1. Demographics. A total of 382 dentists responded. Respondents who did not use LCUs, or who worked in private clinics, or who were from outside Riyadh province were excluded from the statistical analyses $(n=72)$ leaving a total of 310 responses. Out of 310 respondents, there were $111(35.8 \%)$ GPs and the 199 (64.2\%) SPs. Most of the GPs were in the younger age group ranging from 20 to 29 years (56.8\%), whereas $56.3 \%$ of SPs were between 30 and 39 years of age. $69.8 \%$ of the SPs respondents were female and $30.2 \%$ were male. However, $50.5 \%$ of the GPs were female and $49.5 \%$ were male. Most respondents were working in governmental hospitals and only $22.7 \%$ were working in governmental university clinics. Most of the SPs were board certified (45.7\%), and, regarding experience, $51.3 \%$ of SPs exceeded 10 years of experience (Table 1). Specialists were from different specialties with the highest response from operative dentists (34.2\%), followed by AEGD (advanced general dentists) (14.1\%), and then prosthodontists $(13.5 \%)$ (Table 2).

3.2. Knowledge of LCUs. No statistically significant difference was observed between GPs and SPs in their responses to the options of four of the six questions on knowledge of LCUs. Almost half of the GPs (45.9\%) and more than half of SPs (56.8\%) used LED type LCUs. However, $36.9 \%$ of GPs and $29.6 \%$ of SPs were unsure about the type of LCUs they used in their dental clinics. Only $10.8 \%$ of GPs and $8.5 \%$ of SPs correctly answered the question about the proper term of the power output of LCU.

$52.2 \%$ of the GPs and $55.7 \%$ of SPs responded incorrectly to the question regarding the advancement technology of LED LCUs. Approximately half of the respondents (45\%) of GP and (46.7\%) of SPs chose to increase the curing time to overcome any clinical factor that might affect the reduction in power output of the LCUs. However, statistically significant difference was observed in one option of a multiple response question related to properties of resin-based composite materials and knowledge regarding the position between the LCU tip and the resin material surface. $18 \%$ of GPs and $8 \%$ of SPs had responded incorrectly regarding the materials properties "option high bond strength" which indicates statistically significant difference $(p=0.008)$. For the option "hold the light-curing tip as close as possible to the restoration surface," $78.4 \%$ of GPs and $67.8 \%$ of SPs had responded correctly which showed statistically significant difference in their responses $p=0.047$ (Table 3).

3.3. Infection Control and Maintenance. Among the respondents, $75.7 \%$ of GPs and $71.9 \%$ of SPs reported that they inspected and cleaned their LCU before use to ensure it was on the correct setting, with no significant difference between the two groups. Furthermore, most of GPs (60.4\%) and SPs $(68.8 \%)$ used disinfectant with clear barrier technique, with
TABLE 1: Distribution of demographic data of general dentists and specialists.

\begin{tabular}{lcc}
\hline Item & $\begin{array}{c}\text { General } \\
\text { dentist }(n=111) \\
\text { No. }(\%)\end{array}$ & $\begin{array}{c}\text { Specialist }(n=199) \\
\text { No. }(\%)\end{array}$ \\
\hline $\begin{array}{c}\text { Age groups (in years) } \\
20-29\end{array}$ & $63(56.8)$ & $14(7.0)$ \\
$30-39$ & $40(36.0)$ & $112(56.3)$ \\
$40-49$ & $8(7.2)$ & $47(23.6)$ \\
$>50$ & $0(0.0)$ & $26(13.1)$ \\
Gender & & \\
Male & $55(49.5)$ & $60(30.2)$ \\
Female & $56(50.5)$ & $139(69.8)$ \\
Type of practice & & \\
Governmental & $84(75.7)$ & $157(78.9)$ \\
University clinics & $27(24.3)$ & $42(21.1)$ \\
Qualification & & \\
DDS/BDS & $109(98.2)$ & $2(1.0)$ \\
Diploma & $1(0.9)$ & $22(11.1)$ \\
MSc & $1(0.9)$ & $51(25.6)$ \\
PhD & $0(0.0)$ & $33(16.6)$ \\
Board certificate & $0(0.0)$ & $91(45.7)$ \\
Experience (in years) & & $38(19.1)$ \\
$<5$ & $77(69.4)$ & $59(29.6)$ \\
5-10 & $26(23.4)$ & $102(51.3)$ \\
$>10$ & $8(7.2)$ & \\
\hline
\end{tabular}

TABLe 2: Distribution of specialist dentists in different specialties.

\begin{tabular}{lcc}
\hline Specialties & No. & $\%$ \\
\hline Prosthodontics & 27 & 13.5 \\
Endodontics & 22 & 11.1 \\
Periodontics & 3 & 1.5 \\
Orthodontics & 26 & 13.1 \\
Operative dentistry & 68 & 34.2 \\
Paediatric dentistry & 19 & 9.5 \\
Family dentistry & 4 & 2 \\
AEGD & 28 & 14.1 \\
Oral surgery & 2 & 1 \\
Total & 199 & 100 \\
\hline
\end{tabular}

no significant difference between them. However, regarding the use of radiometer device, $48.2 \%$ of SPs and $35.1 \%$ of GPs had responded incorrectly, and $37.7 \%$ of SPs and $52.3 \%$ of GPs chose "not familiar with this device" as their response, which showed a statistically significant difference in their responses $p=0.040$. Respondents were asked about the type of eye protection from the blue light hazards. For the option of "I look away from the blue light," $64 \%$ of GPs and $46.7 \%$ of SPs had responded positively. However, $44.1 \%$ and $40.2 \%$ of them chose "hand-held light shield" for eye protection which showed a statistically significant difference in their responses (Table 3).

The respondents' knowledge of the LCUs use and lightactivated materials was compared in relation to their experience $(<5,5-10, \&>10$ years). There was no statistically significant difference observed in the responses between the respondents based on their years of experience expected for two questions. The first was regarding the new advanced technology of LEDs. $48.7 \%, 56.5 \%$, and $59.1 \%$ of respondents 
TABLE 3: Comparison between general dentists and specialists regarding the knowledge towards light-curing unit (LCU) and light-activating materials, maintenance, and infection control.

\begin{tabular}{|c|c|c|c|c|}
\hline Item & $\begin{array}{c}\text { General dentist } \\
(n=111) \\
\text { No. }(\%)\end{array}$ & $\begin{array}{c}\text { Specialist } \\
(n=199) \\
\text { No. }(\%)\end{array}$ & $\begin{array}{c}\mathrm{X}^{2}- \\
\text { value }\end{array}$ & $\begin{array}{c}p \\
\text { value }\end{array}$ \\
\hline \multicolumn{5}{|c|}{ 1. Knowledge towards light-curing unit (LCU) and light-activating materials } \\
\hline \multicolumn{5}{|l|}{ 1. What type of LCU are you using? } \\
\hline Quartz-tungsten-halogen lights (QTH) & $13(11.7)$ & $20(10.1)$ & 3.583 & 0.465 \\
\hline Plasma-arc lights (PAC) & $4(3.6)$ & $5(2.5)$ & & \\
\hline Argon-ion lasers & $2(1.8)$ & $2(1.0)$ & & \\
\hline Light-emitting diodes (LED) & $51(45.9)$ & $113(56.8)$ & & \\
\hline Unsure & $41(36.9)$ & $59(29.6)$ & & \\
\hline \multicolumn{5}{|c|}{$\begin{array}{l}\text { 2. What is the proper term to describe the amount of power output of the LCU } \\
\text { received over a defined area of resin-based dental material? }\end{array}$} \\
\hline Radiant energy & $24(21.6)$ & $44(22.1)$ & 1.384 & 0.709 \\
\hline Radiant power & $11(9.9)$ & $14(7.0)$ & & \\
\hline Irradiance & $12(10.8)$ & $17(8.5)$ & & \\
\hline Radiant exposure & $64(57.7)$ & $124(62.3)$ & & \\
\hline \multicolumn{5}{|l|}{$\begin{array}{l}\text { 3. Insufficient radiant exposure was found to be associated with which of the } \\
\text { following properties of resin-based composite }(\mathrm{RBC})^{*}\end{array}$} \\
\hline Low mechanical physical properties & $97(87.4)$ & $183(92.0)$ & 1.724 & 0.189 \\
\hline More bacterial colonization & $45(40.5)$ & $84(42.3)$ & 0.084 & 0.77 \\
\hline High bond strength & $20(18.0)$ & $16(8.0)$ & 6.936 & 0.008 \\
\hline Better color stability & $11(9.9)$ & $12(6.0)$ & 1.577 & 0.209 \\
\hline \multicolumn{5}{|c|}{$\begin{array}{l}\text { 4. Location and morphology of the tooth can affect the position between the LCU tip } \\
\text { and the resin material surface. The dentist should always aim to* }\end{array}$} \\
\hline hold the light-curing tip as close as possible to the restoration surface & $87(78.4)$ & $135(67.8)$ & 3.924 & 0.047 \\
\hline hold the light-curing tip up to $10 \mathrm{~mm}$ & $19(17.1)$ & $51(25.6)$ & 2.938 & 0.086 \\
\hline position the light-curing tip at 45 -degree angle & $20(18.0)$ & $42(21.1)$ & 0.427 & 0.514 \\
\hline position the light-curing tip at 90 -degree angle & $41(36.9)$ & $90(45.2)$ & 2.006 & 0.157 \\
\hline \multicolumn{5}{|l|}{$\begin{array}{l}\text { 5. What is the new advancement technology in the latest LED which makes it } \\
\text { different than other types of LCUs? }\end{array}$} \\
\hline It generates monowavelengths & $28(25.2)$ & $58(29.1)$ & 0.594 & 0.743 \\
\hline It generates polywavelengths & $53(47.7)$ & $88(44.2)$ & & \\
\hline It has an advance filter and ventilation fan & $30(27.0)$ & $53(26.6)$ & & \\
\hline \multicolumn{5}{|c|}{$\begin{array}{l}\text { 6. To overcome any clinical factor that might affect the reduction in power output, } \\
\text { you might need to }\end{array}$} \\
\hline store $\mathrm{RBC}$ material in a refrigerator before clinical application & $49(44.1)$ & $97(48.7)$ & 4.523 & 0.104 \\
\hline increase the curing time more than manufacturer's recommendation & $50(45.0)$ & $93(46.7)$ & & \\
\hline choose darker shade of $\mathrm{RBC}$ & $12(10.9)$ & $9(4.5)$ & & \\
\hline
\end{tabular}

2. Maintenance and infection control of light-curing unit (LCU)

1. Do you inspect and clean the LCU before use to ensure it is on the correct setting, in good working order, and free of defects and debris?

Yes

No

2. Do you use radiometer to monitor your LCU output before any clinical session?

Yes

No

Not familiar with this device

3. What do you use to protect your eyes from "blue light hazards?"*

Red laser safety glasses

Light cure shield

Hand-held light shield

Orange protective glasses

My assistant does the curing

I look away from the blue light

4. Infection-control technique was found to affect the light-curing tips and reduce its

irradiance value. What is the technique that has the least negative effect?

Autoclaving

Use of disinfectant solution

Disinfectant with a clear barrier

\begin{tabular}{lccc}
$84(75.7)$ & $143(71.9)$ & 0.529 & 0.467 \\
$27(24.3)$ & $56(28.1)$ & & \\
& & & \\
$14(12.6)$ & $28(14.1)$ & 6.445 & 0.04 \\
$39(35.1)$ & $96(48.2)$ & & \\
$58(52.3)$ & $75(37.7)$ & & \\
& & & \\
$19(17.1)$ & $10(5.0)$ & 12.289 & 0.005 \\
$45(40.5)$ & $81(40.7)$ & 0.001 & 0.973 \\
$30(27.0)$ & $76(38.2)$ & 3.96 & 0.047 \\
$49(44.1)$ & $80(40.2)$ & 0.445 & 0.505 \\
$35(31.5)$ & $55(27.6)$ & 0.525 & 0.467 \\
$71(64.0)$ & $93(46.7)$ & 8.531 & 0.003 \\
& & & \\
$13(11.7)$ & $19(9.5)$ & 2.295 & 0.317 \\
$31(27.9)$ & $43(21.6)$ & & \\
$67(60.4)$ & $137(68.8)$ & & \\
\hline
\end{tabular}

${ }^{*}$ Multiple responses. 
with $<5,5-10$, and $>10$ years of experience, respectively, answered incorrectly $(p=0.048)$. The second question was with the multiple response question regarding the properties of resin composite materials. $96.4 \%$ of respondents with $>10$ years of experience had responded correctly to the option "low mechanical physical properties," when compared to $87 \%$ and $87.1 \%$ of respondents with experience of $<5$ years and 5-10 years $(p=0.028)$, and for the option "more bacterial colonization", $32.7 \%$ of subjects with $>10$ years of experience had responded correctly, while $49.6 \%$ and $42.4 \%$ of subjects with $<5$ years and 5-10 years of experience, respectively, had responded positively $(p=0.037)$ (Table 4$)$.

\section{Discussion}

This study aimed to compare the knowledge between general dentists and specialists working in governmental hospitals and academic institutes in Riyadh, Saudi Arabia, regarding LCUs, their maintenance, personal protection, and infection control. A previous study conducted in Riyadh investigating the knowledge and attitude among dentists in private clinics reported that clinicians showed poor knowledge, maintenance, and attitude toward LCUs [25]. To the best knowledge of the current authors, there is no study performed in Riyadh targeting dentists who work in the governmental sectors.

A questionnaire was distributed online to dentists who use LCUs, working in Riyadh in governmental hospitals or universities. Half of the general practitioners' age ranged between 20 and 29 years having less than five years of experience, while half of the specialists' age ranged between 30 and 39 years having more than ten years of experiences. The percentages of male/female of the general practitioners were $49.5 / 50.5 \%$ while the specialists $30.2 / 69.8 \%$.

The type of LCUs most used according to the respondent is the light-emitting diodes (LED) (45.9\% GP and 56.8\% specialists). This result is in accordance with a study conducted to evaluate dentists' knowledge regarding LCUs in Edinburgh and northern Turkey [22, 24]. It could be attributed to the fact that LED units are lightweight, portable, and more efficient than other types of LCUs [27]. However, less than half of the dentists ( $47.7 \%$ of general practitioners and $44.2 \%$ of specialists) were familiar with technicalities of LED units and were well informed of the new advancement. Understanding about LCU's type and its power output is essential to ensure successful polymerization of light-curing material, surprisingly $36.9 \%$ of general practitioners were "unsure" about the type they are using along with nearly one-third of the specialists (29.6\%) in the present study. This may indicate that practitioners are not attentive enough to LCU product descriptions and do not realize the importance of applying a proper light-curing technique.

Knowledge of the LCU's irradiance and the energy to properly cure composite resin is essential. However, it has been shown in previous studies that a majority of dentists are not aware of this information $[22,23]$. The present result is in accordance with the previous studies, wherein only $10.8 \%$ of the general practitioners and $8.5 \%$ of the specialists were familiar with the radiometric term "irradiance."
Operator technique is one of the factors that affect the radiant exposure delivery to a restoration. It is well documented that there was an improvement in the total amount of curing energy delivered after students had received the proper instructions on using LCU [28-30]. Positioning the LCU tip as close as possible and perpendicular to the restoration maximizes the amount of energy to RBC [31]. The percentage of the general practitioners and specialists in the present study who reportedly position the LCU tip at a proper distance is $78.4 \%$ and $67.8 \%$, respectively, while only a minority of the dentists (36.9\% GP and $45.2 \%$ specialists) reported that they hold the tip at a proper angle.

Determining whether or not a composite restoration is completely cured is one of the largest challenges in clinical practice [32]. In this study clinicians were asked how to overcome any clinical factor that might affect the reduction in power output. $45 \%$ and $46.7 \%$ of general practitioners and specialists, respectively, choose to "increase the curing time more than the manufacturer's recommendation." Several studies indicate that increasing the light-curing exposure time results in higher overall radiant exposure reaching the RBC layer, thus obtaining better polymerization [16, 33-35]. On the other hand, $44.1 \%$ of general practitioners and $48.7 \%$ of specialists responded incorrectly by choosing to store $\mathrm{RBC}$ material in a refrigerator before clinical application. This is a recommended step when using self-curing composite material [32].

Clinicians must understand the principles of light-curing because improper curing of composites can dramatically affect its physical and chemical properties [36]. This study found that the majority of general dentist $(87.4 \%)$ and specialists (92\%) had appropriate understanding of materialrelated science regarding insufficient radiant exposure on the mechanical and optical properties of RBC.

The study revealed that the majority of general dentists (75.7\%) and specialists (71.9\%) inspect and clean the LCU before use and ensure that it is on the correct setting, in good working order, and free of defects and debris, which is in accordance with one of the light-curing guidelines for practitioners [37]. The result is in contrast with Kopperud et al.'s study which showed that only $26.0 \%$ of the respondents did visual checks of the lamp's lens or light guide for scratches, spots, or foreign bodies [23].

At the same time, when the clinicians were asked if they used a radiometer to monitor their LCU output before any clinical session, an affirmative response was obtained from only $12.6 \%$ and $14.1 \%$ of general practitioners and specialists, respectively. A little over one-third of the GPs (35.1\%) did not use radiometer devices to check the LCU, while $52.3 \%$ were unfamiliar with the device.

Similarly, the responses for the specialists were also alarming, wherein $48.2 \%$ were not using the device and $37.7 \%$ were unfamiliar with it. These results are in accordance with a study designed to evaluate light intensity output of LCUs used in private clinics in Riyadh, where it was reported that most of the dentists did not measure the light intensity output [25].

Several studies, worldwide, showed that many offices have been delivering inadequate energy when using LCUs 
TABLE 4: Comparison between general dentists and specialists on their knowledge towards their use of light-curing unit (LCU) and lightactivated materials based on their experience.

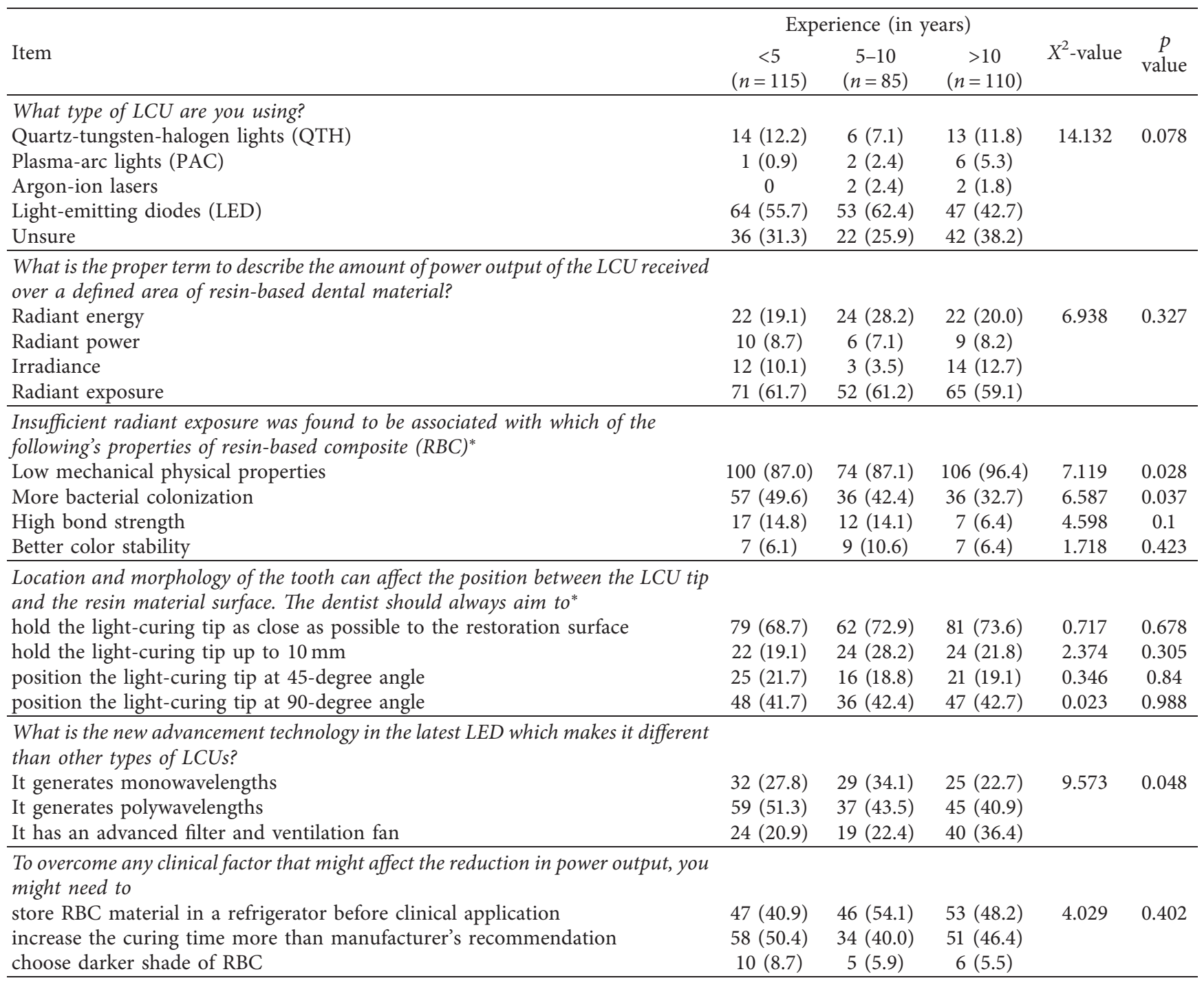

${ }^{*}$ Multiple responses.

$[26,28,38-43]$. Some of the studies were conducted in different areas in Saudi Arabia including governmental institutes, dental schools, and private clinics [25, 26, 44, 45]. All concluded and agreed that regular assessment and standardized maintenance protocol for LCUs are recommended to ensure clinically acceptable outcome from the devices $[26,44,45]$. This suggests that a large portion of dental clinicians in the present study show a high possibility for incorrect curing procedure and signifies that they do not follow the proper guidelines before using LCUs. A possible explanation for those practitioners who do not use a radiometer is that those who work in public clinics were probably not involved in LCU selection and purchase and that light measurement could be performed by others, e.g., dental assistant, radiation safety officer, or the unit manufacturer, without their knowledge. In addition, some LCUs have color indicators to reflect the value of the irradiance without a numerical value, so the unit can be monitored to some extent.
The use of eye protection is mandatory when using LCUs since they emit blue light, which has been proved to have negative effects on the retina [46-49]. It is recommended by all LCU manufacturers to use protective shields or eyewear to block and minimize the bright blue light [46]. Most of the general practitioners' responses (64\%) regarding this matter was that "they are looking away from light" during curing and $46.7 \%$ of specialist do the same. The result is in agreement with a study performed in Norway among dentists in the public dental service where one-third of the dentists showed insufficient eye protection when lightcuring restorations [46]. The explanation for the present result is either most of the dentists look away from the light even after wearing eye protection or using shield or simply they are not aware of the consequences of moving the light away from the restoration. Looking away from the light and from the material to be cured is not recommended since it will reduce the amount of energy delivered if the light 
position is altered, and it is preferable that the operator should observe the site while wearing eye protection [22].

The most common methods of maintaining the sterility of LCUs are by using an autoclave, wiping with a disinfectant, or using a clear barrier. The current study revealed that the majority use a clear barrier to have the least negative effects in the power value, $60.4 \%$ of general practitioners and $68.8 \%$ of specialists. The percentage of the clinicians who use autoclaving is $27.9 \%$ GPs and $21.6 \%$ SPs, and those who use disinfectant was the lowest, $11.7 \%$ GPs and 9.5\% for SPs. Using of clear barrier was the most common method in the governmental clinics and could be due to its convenience and noninvasiveness and that it is a cost-effective alternative compared to other techniques.

In general, there is no significant relation found between experience (years in practice) and knowledge of LCUs and material science. This finding is supported by earlier studies. Santini and Tuloglu assessed knowledge of material science among a group of dentists and found no positive relationship between years in practice and material science $[22,24]$. Ueda compared dentin bonding effectiveness of self-etch bonding cement applied by dental students and experienced clinicians, and no discernible relation was found [31].

Regarding the present study, it is considered to have a low response rate in certain specialties. One explanation is that perhaps some specialists felt less confident or lacked the knowledge regarding the subject and therefore decided against responding. A possible explanation for operative dentists having the highest response rate could be the frequent use of LCUs in their daily practice.

Within the limitation of the present study, it was found that general practitioners and dental specialists possess insufficient knowledge of LCUs and inadequate information about LCU maintenance and eye protection. Generally, there was no significant difference in knowledge among dentists in relation to their years of experience. Based on the present findings, it can be stated that there is an immense need for educational programs, training, and guidance toward LCUs.

\section{Data Availability}

The data used to support the findings of this study can be made available upon request to the corresponding author.

\section{Conflicts of Interest}

There are no conflicts of interest.

\section{Authors' Contributions}

All the authors have contributed significantly and agree with the manuscript.

\section{References}

[1] F. F. Demarco, K. Collares, M. B. Correa et al., "Should my composite restorations last forever? Why are they failing?" Brazilian Oral Research, vol. 31, Article ID e56, 2017.
[2] G. G. Nascimento, M. B. Correa, N. Opdam, and F. F. Demarco, "Do clinical experience time and postgraduate training influence the choice of materials for posterior restorations? Results of a survey with Brazilian general dentists," Brazilian Dental Journal, vol. 24, no. 6, pp. 642-646, 2013.

[3] S. D. Heintze and V. Rousson, "Clinical effectiveness of direct class II restorations-a meta-analysis," The Journal of Adhesive Dentistry, vol. 14, pp. 407-431, 2012.

[4] S. Binalrimal, S. Alamry, M. Alenezi, N. Alfassam, and S. Almuammar, "Evaluation of light-curing intensity output and students' knowledge among dental schools in Riyadh city," Open Access Macedonian Journal of Medical Sciences, vol. 8, no. D, pp. 178-181, 2020.

[5] A. Knezevic, D. Zeljezic, N. Kopjar, and Z. Tarle, "Cytotoxicity of composite materials polymerized with LED curing units," Operative Dentistry, vol. 33, no. 1, pp. 23-30, 2008.

[6] A. Santini, C. Watterson, and V. Miletic, "Temperature rise within the pulp chamber during composite resin polymerisation using three different light sources," The Open Dentistry Journal, vol. 2, no. 1, pp. 137-141, 2008.

[7] R. B. Price, M. E. McLeod, and C. M. Felix, "Quantifying light energy delivered to a class I restoration," Journal (Canadian Dental Association), vol. 76, Article ID a23, 2010.

[8] R. B. Price, J. L. Ferracane, and A. C. Shortall, "Light-curing units," Journal of Dental Research, vol. 94, no. 9, pp. 1179-1186, 2015.

[9] K. D. Jandt and R. W. Mills, "A brief history of LED photopolymerization," Dental Materials, vol. 29, no. 6, pp. 605-617, 2013.

[10] N. Krämer, U. Lohbauer, F. García-Godoy, and $\mathrm{R}$ Frankenberger, "Light curing of resin-based composites in the LED era," American Journal of Dentistry, vol. 21, pp. 135142, 2008.

[11] B. F. Alam, T. Nayab, T. A. Najmi, and U. Khan, "Knowledge of Pakistani dentist towards light curing units-a cross sectional analysis," Journal of the Pakistan Dental Association, vol. 29, no. 02, pp. 81-86, 2020.

[12] F. A. Rueggeberg, M. Giannini, C. A. G. Arrais, and R. B. T Price, "Light curing in dentistry and clinical implications: a literature review," Brazilian Oral Research, vol. 31, p. e61, Article ID e61, 2017.

[13] K. A. O. R. d. F. Cardoso, D. C. Zarpellon, C. F. L. Madruga, J. A. Rodrigues, and C. A. G. Arrais, "Effects of radiant exposure values using second and third generation light curing units on the degree of conversion of a lucirin-based resin composite," Journal of Applied Oral Science, vol. 25, no. 2, pp. 140-146, 2017.

[14] F. H. B. Aguiar, C. R. Lazzari, D. A. N. L. Lima, G. M. B. Ambrosano, and J. R. Lovadino, "Effect of light curing tip distance and resin shade on microhardness of a hybrid resin composite," Brazilian Oral Research, vol. 19, no. 4, pp. 302-306, 2005.

[15] R. B. Price, T. Dérand, R. W. Loney, and P Andreou, "Effect of light source and specimen thickness on the surface hardness of resin composite," American Journal of Dentistry, vol. 15, pp. 47-53, 2002.

[16] L. Ceballos, M. V. Fuentes, H. Tafalla, A Martínez, J Flores, and J Rodríguez, "Curing effectiveness of resin composites at different exposure times using LED and halogen units," Medicina Oral, Patologia Oral Y Cirugia Bucal, vol. 14, pp. E51-E56, 2009.

[17] J. Zorzin, E. Maier, S. Harre et al., "Bulk-fill resin composites: polymerization properties and extended light curing," Dental Materials, vol. 31, no. 3, pp. 293-301, 2015. 
[18] B. A. Scott, C. A. Felix, and R. B. Price, "Effect of disposable infection control barriers on light output from dental curing lights," Journal (Canadian Dental Association), vol. 70, pp. 105-110, 2004.

[19] R. S. Beolchi, C. Moura-Netto, R. M. Palo, C. R. G. Torres, and B. Pelissier, "Changes in irradiance and energy density in relation to different curing distances," Brazilian Oral Research, vol. 29, no. 1, pp. 1-7, 2015.

[20] F. E. Martin, "A survey of the efficiency of visible light curing units," Journal of Dentistry, vol. 26, no. 3, pp. 239-243, 1998.

[21] H. Milly and A. Banerjee, "Evaluating the clinical use of lightemitting diode vs halogen photocuring units," Oral Health \& Preventive Dentistry, vol. 16, pp. 21-25, 2018.

[22] A. Santini and S. Turner, "General dental practitioners' knowledge of polymerisation of resin-based composite restorations and light curing unit technology," British Dental Journal, vol. 211, Article ID E13, 2011.

[23] S. E. Kopperud, H. V. Rukke, H. M. Kopperud, and E. M. Bruzell, "Light curing procedures-performance, knowledge level and safety awareness among dentists," Journal of Dentistry, vol. 58, pp. 67-73, 2017.

[24] S. . Ö. Nuray Tüloğlu, E. Ş. Tunç, S. Canbaz, and Ş. Bayrak, "Knowledge and attitudes of dental clinicians regarding lightcuring units in northern Turkey," Clinical Dentistry and Research, vol. 40, pp. 26-34, 2016.

[25] L. Alqabbaa, M. Alsenani, N. Alsaif, R. Alsaif, and S. Binalrimal, "Light intensity output of visible light communication units and clinicians' knowledge and attitude among Riyadh private clinics," Journal of Conservative Dentistry, vol. 21, no. 6, pp. 667-670, 2018.

[26] M. Al Shaafi, A. Maawadh, and M. Al Qahtani, "Evaluation of light intensity output of QTH and LED curing devices in various governmental health institutions," Operative Dentistry, vol. 36, no. 4, pp. 356-361, 2011.

[27] F. A. Rueggeberg, "State-of-the-art: dental photocuring-a review," Dental Materials, vol. 27, no. 1, pp. 39-52, 2011.

[28] M. Federlin and R. Price, "Improving light-curing instruction in dental school," Journal of Dental Education, vol. 77, no. 6, pp. 764-772, 2013.

[29] S. Seth, C. J. Lee, and C. D. Ayer, "Effect of instruction on dental students; ability to light-cure a simulated restoration," Journal (Canadian Dental Association), vol. 78, Article ID c123, 2012.

[30] A. A. Suliman, A. A. Abdo, and H. A. Elmasmari, "Training and experience effect on light-curing efficiency by dental practitioners," Journal of Dental Education, vol. 84, no. 6, pp. 652-659, 2020.

[31] M. Ueda, A. Mine, J. De Munck, T. Hakogi, B. Van Meerbeek, and T. Kuboki, "The effect of clinical experience on dentine bonding effectiveness: students versus trained dentists," Journal of Oral Rehabilitation, vol. 37, no. 9, pp. 653-657, 2010.

[32] E. Mahn, "Clinical criteria for the successful curing of composite materials," Revista Clínica de Periodoncia, Implantología y Rehabilitación Oral, vol. 6, pp. 148-153, 2013.

[33] M. M. AlShaafi, "Factors affecting polymerization of resinbased composites: a literature review," The Saudi Dental Journal, vol. 29, no. 2, pp. 48-58, 2017.

[34] L. C. Sobrinho, M. F. d. Goes, S. Consani, M. A. C. Sinhoreti, and J. C. Knowles, "Correlation between light intensity and exposure time on the hardness of composite resin," Journal of Materials Science: Materials in Medicine, vol. 11, no. 6, pp. 361-364, 2000.
[35] F. H. Rasetto, C. F. Driscoll, and J. A. Fraunhofer, "Effect of light source and time on the polymerization of resin cement through ceramic veneers," Journal of Prosthodontics, vol. 10, no. 3, pp. 133-139, 2001.

[36] H. A. A. E. Ahmad Ali Abdo, "Effect of contamination, damage and barriers on the light output of light-curing units," The Open Dentistry Journal, vol. 13, pp. 196-202, 2019.

[37] J. A. Platt and R. B. Price, "Light curing explored in Halifax," Operative Dentistry, vol. 39, no. 6, pp. 561-563, 2014.

[38] G. A. Maghaireh, H. Alzraikat, and N. A. Taha, "Assessing the irradiance delivered from light-curing units in private dental offices in Jordan," The Journal of the American Dental Association, vol. 144, no. 8, pp. 922-927, 2013.

[39] G. C. Santos, M. J. Santos, O. El-Mowafy, and W El-Badrawy, "Intensity of quartz-tungsten-halogen light polymerization units used in dental offices in Brazil," The International Journal of Prosthodontics, vol. 18, pp. 434-435, 2005.

[40] O. El-Mowafy, W. El-Badrawy, D. W. Lewis et al., "Efficacy of halogen photopolymerization units in private dental offices in Toronto," Journal (Canadian Dental Association), vol. 71, p. 587, 2005.

[41] V. Hegde, S. Jadhav, and G. B. Aher, "A clinical survey of the output intensity of 200 light curing units in dental offices across Maharashtra," Journal of Conservative Dentistry: JCD, vol. 12, pp. 105-108, 2009.

[42] N. Barghi, D. E. Fischer, and T. Pham, "Revisiting the intensity output of curing lights in private dental offices," Compendium of Continuing Education in Dentistry (Jamesburg, N. J. 1995), vol. 28, pp. 380-386, 2007.

[43] X. Hao, M. Luo, J. Wu, and S. Zhu, "A survey of power density of light-curing units used in private dental offices in Changchun City, China," Lasers in Medical Science, vol. 30, no. 2, pp. 493-497, 2015.

[44] M. M. Alshaafi, "Evaluation of light-curing units in rural and urban areas," The Saudi Dental Journal, vol. 24, no. 3-4, pp. 163-167, 2012.

[45] H. M. Nassar, R. Ajaj, and F. Hasanain, "Efficiency of light curing units in a government dental school," Journal of Oral Science, vol. 60, no. 1, pp. 142-146, 2018.

[46] M. Rassaei, M. Thelen, R. Abumuaileq, J. Hescheler, M. Lüke, and T. Schneider, "Effect of high-intensity irradiation from dental photopolymerization on the isolated and superfused vertebrate retina," Graefe's Archive for Clinical and Experimental Ophthalmology, vol. 251, no. 3, pp. 751-762, 2013.

[47] N. N. Osborne, C. Núñez-Álvarez, and S. Del Olmo-Aguado, "The effect of visual blue light on mitochondrial function associated with retinal ganglions cells," Experimental Eye Research, vol. 128, pp. 8-14, 2014.

[48] S. Del Olmo-Aguado, C. Núñez-Álvarez, and N. N. Osborne, "Blue light action on mitochondria leads to cell death by necroptosis," Neurochemical Research, vol. 41, no. 9, pp. 2324-2335, 2016.

[49] G. H. Kim, H. I. Kim, S.-S. Paik, S. W. Jung, S. Kang, and I.-B. Kim, "Functional and morphological evaluation of blue light-emitting diode-induced retinal degeneration in mice," Graefe's Archive for Clinical and Experimental Ophthalmology, vol. 254, no. 4, pp. 705-716, 2016. 